\title{
Mafia and psychopathy
}

\author{
ADRIANO SCHIMMENTI ${ }^{1}$, CHIARA CAPRI ${ }^{2}$, DANIELE LA BARBERA ${ }^{2}$ \\ AND VINCENZO CARETTI ${ }^{3},{ }^{1}$ Faculty of Human and Social Sciences, UKE - \\ Kore University of Enna, Enna, Italy; ${ }^{2}$ Experimental Biomedicine and Clinical \\ Neurosciences, University of Palermo, Palermo, Italy; ${ }^{3}$ Psychology, University of \\ Palermo, Palermo, Italy
}

\section{ABSTRACT}

Background In popular culture, Mafia members are often portrayed as ruthless, callous and remorseless, but there is no empirical research on their personality traits.

Aims The goal of this research was to examine levels of psychopathic traits among Mafia members who have been convicted of a criminal offence.

Methods The Psychopathy Checklist-Revised (PCL-R) rated 30 Italian adult male prisoners who had been convicted for Mafia-related crimes (86\% resident in one 6-month period) and 39 next adjacent convicted men who were not enrolled in any criminal organisation.

Results Mafia members obtained lower PCL- $R$ total scores, interpersonal and affective (PCL-R factor 1) scores and lifestyle scores (factor 2 ) than the other offenders. Logistic regression analysis showed that lower PCL-R factor 1 scores with higher factor 2 scores in the absence of a history of substance misuse disorder distinguished Mafia from non-Mafia offenders. A probability curve confirmed an exponential growth in the probability of classification as a Mafia member in relation to lower PCL-R factor 1 scores.

Conclusions Our findings bring new hope for resocialisation of convicted Mafia members, because they showed significant antisocial traits but they maintained a capacity for emotional connection and greater likelihood of engaging with training and resocialisation programmes than other imprisoned offenders in Italy. Copyright (C) 2014 John Wiley $\mathcal{G}$ Sons, Ltd.

\section{Background}

Mafia-type organisations present a major social problem worldwide (Dean et al., 2010). The original Mafia (also known as Cosa Nostra) emerged in Sicily more than 100 years ago as an association of criminal groups, known as 'families', that shared a common organisational structure and code of conduct (Dickie, 2005; Lupo, 2009). Over time, use of the term Mafia has spread to other criminal organisations, and today, it refers broadly to any organised criminal network 
operating with similar structure, methods and interests. Article 416 bis of the Italian Penal Code defines an association as being of Mafia type 'when those belonging to the association exploit the potential for intimidation which their membership gives them, and the compliance and code of silence which membership entails and which lead to the committing of crimes, the direct or indirect assumption of management or control of financial activities, concessions, permissions, enterprises and public services for the purpose of deriving profit or wrongful advantages for themselves or others'.

Sociological and psychological studies suggest that the sense of identity experienced by Mafia members is inextricably nested in the families and the community to which they belong and that the group identification represents a core dimension for explaining their attitudes and behaviours (e.g. Di Maria, 1997; Bovenkerk, 2000; Lo Verso and Lo Coco, 2004; Dean et al., 2010). According to Lo Verso and Lo Coco (2004), for example, Italian Mafia organisations actively deter individualism in order to strengthen their own interests; Mafia members are not allowed to gain personal authority without the help of their boss and their family, so they are entirely reliant on the organisation for their criminal career development and for receiving social and psychological support. Thus, members may feel virtually incapable of acting against the will of the group: after the individuals join actively in the Mafia organisation, they lose the ability to differentiate between their own goals, objectives, friends and enemies and those of their family (Fabj, 1998; Bovenkerk, 2000).

Group identification is, however, likely to be only part of the process of becoming mafiosi. Examination of the few clinical interviews recorded with Mafia members and their relatives suggests that personality traits may play a relevant role in this: past members reported that from childhood, they viewed the Mafia as a way to obtain pride, prestige and money. They reported feeling no guilt for crimes, including murder, and few could recall ever feeling afraid but rather feeling respected by others and seeing themselves as 'honourable' criminals with strong values and beliefs (Fabj, 1998; Lo Verso and Lo Coco, 2004).

The inflated self-representation and the lack of guilt observed in many Mafia members could suggest the presence of psychopathic traits. 'Psychopathy' is characterised by a constellation of interpersonal, affective and behavioural characteristics: it entails features such as grandiosity, egocentricity, deceptiveness, shallow emotions, impulsivity, irresponsibility and lack of empathy, guilt and remorse, together with the violation of social expectations and the legal norms (Hare and Neumann, 2008). This construct thus includes several traits that seem to fit well with some behaviours of mafiosi, such as the many murders during the 'second Mafia war' in Italy in the early 1980s when relatives of members from rival families, including children and women, were brutally murdered by horrific techniques, such as being liquefied into acidic compounds, suggesting impaired or absent empathy. On the other hand, belonging to criminal organisations is not prototypical of psychopathy, as people with this problem are usually 
unable to follow codes that could restrict their personal manipulation and exploitation of others (Hare, 1998).

As there has been little if any formal evaluation of mafiosi, our aim was to assess psychopathy in a sample of 30 convicted and imprisoned Mafia members and compare their scores on the PCL-R with those of other convicted prisoners who were not affiliated to any criminal organisation.

We hypothesised that Mafia members would show a higher level of psychopathic traits than the other offenders; in particular, we expected that Mafia members would show higher levels of the dysfunctional interpersonal and affective traits of psychopathy.

\section{Method}

\section{Participants}

All the participants were recruited from the list of convicted offenders in the Pagliarelli prison in Palermo, Italy. Initial screening of institutional files allowed selection of all those who had been convicted of Mafia-related crimes who could be available for research (i.e. sentenced under Article 416 bis of the Italian Penal Code for committing a Mafia-related crime, but they did not receive the additional sentence under Article 41 bis of the Prison Administration Act 1975, which is a restrictive measure on people imprisoned for particular crimes, preventing any meeting with third parties). The comparison group was recruited from the next adjacent cases in the list of offenders convicted of non-Mafia-related crime.

The largest group of Mafia members was of men affiliated to Cosa Nostra (14, $47 \%)$; the others were to the Camorra (8, 27\%), 'Ndrangheta $(4,13 \%)$ and Sacra Corona Unita $(4,13 \%)$ organisations. The mean age of the Mafia members was 44.6 years [standard deviation (SD) 9.1; range 23-68], and their average length of sentence was 7.94 years (SD 5.55). Most of them were married $(25,83 \%)$ and had a low level of education (mean 7.3 years, SD 3.2). Seven of the Mafia members (23\%) had been convicted of murder, 17 (57\%) for other violent offences (robbery with violence, aggravated assault and wounding with intent) and the remainder for crimes including trafficking in narcotics, illegal possession of weapons, possession of stolen goods, extortion, fraud, sexual exploitation and kidnapping. Also, a few of the Mafia members committed crimes that were unrelated with their participation in the Mafia business, including one adult rape, two auto thefts, one hit and run when driving while intoxicated and three break and enters. Three of the Mafia members had a history of substance use disorder (SUD) (alcohol, cannabis or cocaine).

The members of the comparison group had been convicted of similar crimes, including murder, sexual exploitation, adult rape, child sexual abuse, armed robbery, aggravated assault, trafficking in narcotics and weapon, break and enter, and driving while intoxicated.

None of the participants reported any current physical or mental disorder. 


\section{Procedures}

The study was approved by the Italian Department of Prison Administration and by the prison's ethics committee. All participants were introduced to the aims of the study. They were told that the data would be recorded according to a strict procedure to guarantee the confidentiality of information, and they signed informed consent prior to participation. They were also assured that they could withdraw from the study at any time and request removal of their responses from the database, but none of the participants did withdraw.

Data were collected between September 2012 and March 2013. The interview took place individually, in a quiet room where inmates are usually interviewed by their educators. For safeguarding reasons, a police officer was available within calling distance.

\section{The measure}

The Psychopathy Checklist-Revised (PCL-R; Hare, 2003) is the most used clinical measure for assessing psychopathy. We rated after a semi-structured interview of between 1 and 3 hours, according to the individual's answers, prison file review and collateral information. Each of us had completed the accredited training course for the PCL-R. The 20 items were rated on a 3-point scale according to the extent to which they applied to a given individual and according to prescribed criteria. Eighteen of the items form four dimensions: interpersonal (e.g. pathological lying and conning/manipulative), affective (e.g. shallow affect and callous/lack of empathy), lifestyle (e.g. impulsivity and irresponsibility) and antisocial (e.g. poor behavioural controls and criminal versatility). The interpersonal/affective and lifestyle/antisocial dimensions comprise, respectively, the higher-order PCL-R factors 1 and 2 . The remaining two items (promiscuous sexual behaviour and many short-term marital relationships) do not load on either dimension but contribute to the total PCL-R score. Total PCL-R scores can vary from 0 to 40 (Hare and Neumann, 2008).

Cronbach's alpha was 0.81 for the PCL-R total score and 0.79 and 0.84 for factors 1 and 2, respectively, with the alpha for the facets ranging from 0.78 (affective) to 0.83 (lifestyle). Two of the authors independently rated 20 random cases (29.0\%), obtaining an average intraclass coefficient correlation (ICC) for PCL-R total score of 0.90 , with ICC for factor and facet scores ranging from 0.84 (affective) to 0.92 (PCL-R factor 2).

\section{Statistical analysis}

Descriptive statistics were computed for all the observed variables. Student's t-test and Pearson's chi-square were performed for assessing differences between Mafia members and other inmates. A stepwise logistic regression based on Wald statistic $(F$-to-enter $<0.05, F$-to-remove $>0.10)$ was undertaken to examine the 
associations between psychopathic traits, sociodemographic variables and the classification of participants into group (Mafia/non-Mafia). A p-value of 0.05 was set as the critical level for statistical significance.

\section{Results}

Thirty men convicted of Mafia-related and 39 of non-Mafia-related crimes completed the study, $86 \%$ and $78 \%$ eligible participants, respectively. Participants and non-participants did not differ in terms of age [Mafia members: $t_{(43)}=0.90$, $p=0.37$, ns; other inmates: $t_{(48)}=1.08, p=0.28$, ns] or nature of committed crimes [violent vs non-violent crimes; Mafia members: $\chi_{(1)}^{2}=1.14, p=0.29$, ns; other inmates: $\chi_{(1)}^{2}=0.71, p=0.40$, ns]. Table 1 shows the sociodemographic variables and the psychopathic trait descriptors by group, with tests for differences between Mafia members and other criminals. There were no Mafia members who scored 30 or above (a generally accepted threshold for psychopathy), and only three of them $(10.0 \%)$ scored between 20 and 29. By contrast, in the comparison group, four men (10\%) scored above 30, and a further 18 (46\%) obtained scores between 20 and 29. The Mafia members, as a group, had significantly lower factor 1 (interpersonal/affective) and total PCL-R scores than the comparison offenders, but their factor 2 (antisocial lifestyle) scores were similar.

As Table 1 also illustrates, Mafia members were similar to the comparison group men with respect to age, level of education or sentence length, but they were more likely to be married and they were less likely to have a history of SUD.

Next, we compared the PCL-R scores of our comparison participants with the PCL- $\mathrm{R}$ scores of the male prisoners who had participated in the Italian PCL-R validation study (Caretti et al., 2011). This was to check whether they were representative of the degree of psychopathy among Italian male prisoners more generally. The results of this analysis showed that the PCL-R scores in our comparison group did not differ from those reported in the Italian validation study, for PCL-R total score $\left[t_{(153)}=0.70, p=0.48\right.$, ns], PCL-R factor 1 score $\left[t_{(153)}=0.60, p=0.55, \mathrm{~ns}\right]$ or PCL-R factor 2 score $\left[t_{(153)}=0.89, p=0.37, \mathrm{~ns}\right]$.

A stepwise logistic regression analysis was performed, with group membership (Mafia members vs other criminals) as the binary dependent variable. In the first step, all the sociodemographic variables (age, education, marital status, years of conviction and history of SUD) were entered stepwise into the model as the independent variables; only having a history of SUD distinguished the groups, being about 50 times less likely in the Mafia group [odds ratio $(\mathrm{OR})=0.02$, 95\% confidence interval $(\mathrm{CI})$ 0.004-0.109; netnWald $\left._{(1)}=23.7, p<0.001\right]$. In the second step, all the PCL-R scales were entered stepwise into the model (Table 2); having a history of SUD remained a significant discriminator $(\mathrm{OR}=0.003$, CI 0.001-0.007). PCL-R factor 1 (interpersonal/affective) scores $(\mathrm{OR}=0.75, \mathrm{CI}=0.59-0.95)$ - lower in the Mafia group - and the antisocial facet 


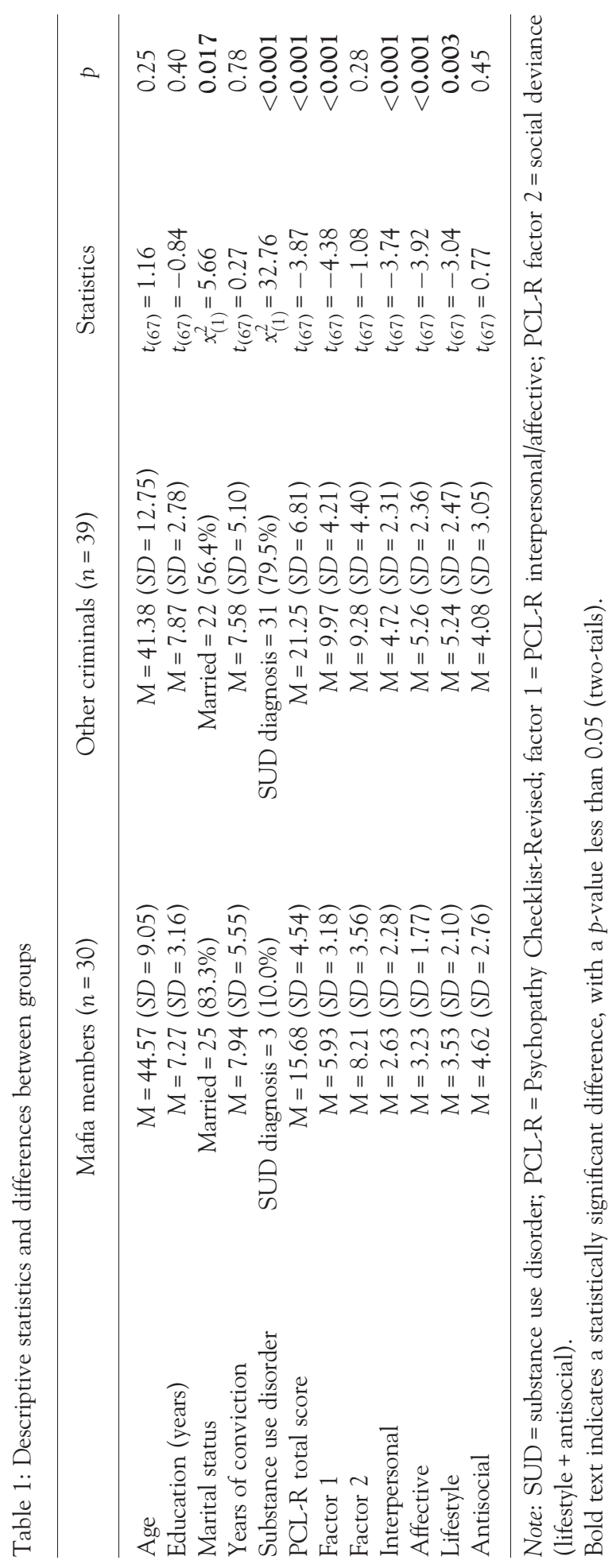


scores $(\mathrm{OR}=1.66, \mathrm{CI}=1.07-2.70)-$ higher in the Mafia group - added to the model; the other PCL-R scales were removed from the model (all $p>0.50$ ).

This final model was significant (omnibus test $\chi_{(3)}^{2}=55.12, p<0.001$; Hosmer and Lemeshow $\left.\chi_{(8)}^{2}=4.00, p=0.86\right)$, and it explained $74.5 \%$ of Nagelkerke's pseudovariance. The estimated probability of being predicted as a Mafia member on the basis of participants' PCL-R factor 1 scores is plotted in Figure 1.

Figure 1 shows that the estimated probability of being included in the Mafia group had an almost linear relationship with PCL-R factor 1 score, with Mafia members showing lower probability of displaying significant interpersonal and affective traits of psychopathy.

\section{Discussion}

Research with Mafia samples is very difficult, because Mafia members rarely seek out psychotherapy, and they are particularly reluctant to be involved in diagnostic interviews and psychological studies, but we successfully recruited a majority of those serving a sentence in one Italian prison in order to explore their personality traits, as Lo Verso and Lo Coco (2004) emphasised the importance of trying to do this. Contrary to our prediction, we found that Mafia group membership was associated with less evidence of disorder in affective and interpersonal traits and less use of substances. There was no difference between the two criminal groups in terms of educational levels (both low), age or sentence length.

Although our findings were against prediction, they do fit well with some logic. It is well recognised that SUDs are common among offenders generally (Boden et al., 2012; Peters et al., 2012), which is what we also found, but Mafia members are required to appear reliable, maintain power and adhere to the internal representations and principles of their organisation, and such skills tend to be impaired by substance use. It may be that substance misusers would be less likely to be selected for Mafia membership (as they would be viewed as liabilities), and if selected by chance, their involvement would be short lived.

Table 2: Results of stepwise logistic regression for classification of Mafia members

\begin{tabular}{lrrrc}
\hline & $\operatorname{Exp}(B)$ & Wald $_{(1)}$ & \multicolumn{1}{c}{$p$} & Confidence interval (95\%) \\
\hline Substance use disorder & 0.003 & 13.31 & $<0.001$ & $0.001-0.007$ \\
PCL-R factor 1 & 0.750 & 5.64 & 0.018 & $0.591-0.951$ \\
PCL-R antisocial & 1.663 & 5.01 & 0.025 & $1.065-2.697$ \\
\hline
\end{tabular}

Note: PCL-R = Psychopathy Checklist-Revised.

Goodness of fit: $87.5 \%$. 


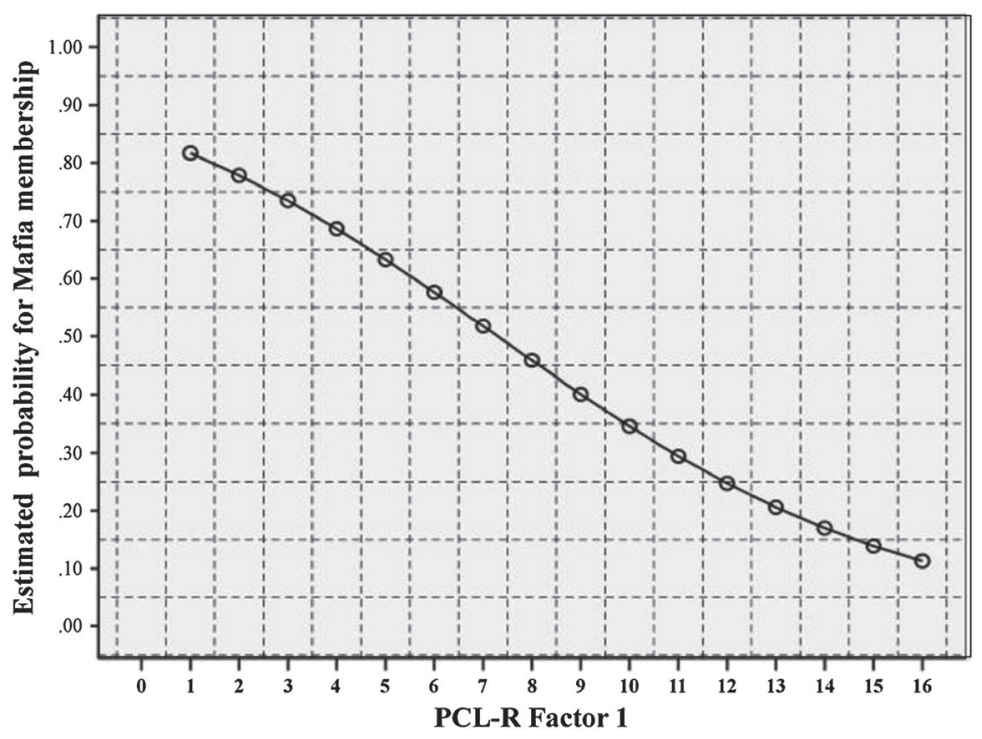

Note: PCL-R Factor 1 = Psychopathy Checklist-Revised Interpersonal/Affective factor. The effects of PCL-R Antisocial facet and history of substance use disorder are kept constant in the equation. Coordinates of the probability curve were generated by logarithmic transformation of the following equation: $y=\beta$ of the constant in the logistic regression model $+($ PCL-R Factor 1 scores $* \beta$ PCL-R Factor 1 scores $)+($ Mean of Antisocial Facet $* \beta$ Antisocial Facet $)+($ Mean Substance Use Disorder $* \beta$ Substance Use Disorder).

Figure 1: Estimated probability of being classified as a Mafia member based on the interpersonal/ affective factor of the Psychopathy Checklist-Revised

Mafia members were more likely to be married than other participants. This is probably related to both psychological and sociological factors (Di Maria, 1997; Lo Verso and Lo Coco, 2004). For some individuals, the process of internalisation of the Mafia family can convey a desire for creating one's own family with shared values and idealised characteristics through marriage, and for others, the marriage may occur with members of other families, which can strengthen territorial control. Also, according to Di Maria (1997), the children of Mafia members internalise the implicit social values of their fathers and extend these values towards any social relationship in later life stages: this can produce a 'Mafia way of thinking and feeling' based on repetition of relational patterns and conformity to Mafia values.

It was surprising that no Mafia member had a PCL-R score above 30, when four - about $10 \%$ - of the comparison group did so and that, as a group, they had so much lower scores than the other participants in the interpersonal, affective and lifestyle traits of psychopathy. This means that they were less 'manipulative', 'Machiavellian', 'narcissistic', 'unemotional', 'parasitic' and/or 
'impulsive' than the other participants (Caretti et al., 2012). Further, during the interviews, they often expressed concerns for their children and their families, and they had never ceased to write and call them. Such expressions of attachment were less apparent among the comparison men. Even criminal actions for most of the Mafia members were led by loyalty to their families or adherence to the family's 'mission' rather than personal interest; however, they also showed infantile and dependent personality traits, demonstrated by their adherence, submission and obedience to the willingness of their boss and the organisation. Many of them, when asked about their participation in criminal actions, said something like 'My boss ordered it, and I had to do it. I could not act in any other way'. This somewhat resembled the 'superior orders defence' of the Nazi criminals in the Nuremberg trials (Sprecher, 1999), summarised in the words 'Befehl ist Befehl' ('an order is an order'). Furthermore, the PCL-R interviews showed that many Mafia members had a generally intact capacity to form affective bonds - in their private lives and as mafiosi. It is possible that these individuals compartmentalised their lives and behaviours - on the one side, the Mafia affairs, on the other side, their positive feelings and affects towards relatives and friends. This sometimes led to difficulties in scoring PCL-R items, especially in the affective dimension; on 'lack of remorse or guilt' or 'callous/lack of empathy', for example, we found that many Mafia members did not show the characteristics needed for receiving the highest score (2) because the item indicators were applied to them only to a certain extent or only in specific contexts; moreover, often, we found too many exceptions in the match with the item description, sometimes, even to give a score of 1 . In contrast, we rarely found exceptions in applying the highest score on these items to the most violent criminals in the comparison group.

Results of the logistic regression analysis confirmed that high levels of antisocial traits coupled with low levels of interpersonal/affective traits of psychopathy were characteristics of the Mafia group, together with not having a history of SUD. Moreover, when SUD and antisocial traits were kept constant in the equation model, an inverse and almost linear relationship emerged between the interpersonal/affective traits of psychopathy and the estimated probability of being classified as a Mafia member in the sample - from more than $80 \%$ when the lowest PCL-R factor 1 scores were observed to about $10 \%$ for people with the highest factor 1 scores. If future research on the topic was to confirm this result, it may bring new hope for the treatment of Mafia members (Lieb, 2006). As they are capable of emotional connection and empathy, they are much more likely to be able to engage with treatment programmes, if offered, than offenders with high psychopathy scores (Rice et al., 1992; Hare, 1998; Grann et al., 1999; McWilliams, 2011).

Our study is, as far as we know, the first to study Mafia members in this way, but some limitations are noteworthy. First, the small sample size made it impossible to check for possible differences in psychopathic traits between 
members of different Mafia-type organisations. Second, the study did not allow us to distinguish between white-collar criminals and other criminals in the Mafia subsample. Third, we were not able to interview any Mafia boss because the Article 41 bis of the Italian Prison Administration Act 1975 prevents research interviews; it is possible that at higher levels within Mafia organisations, or among those who never get caught, psychopathic traits are more severe, but we could not address this question. Fourth, our study was cross-sectional, so we cannot do more than speculate on the direction of relationships between psychopathy scores and group membership.

\section{Conclusions}

In the first study of psychopathic traits among Mafia members, we found that not only did they not score at the highest levels on the PCL-R, but, as a group, their score on the affective/interpersonal dimension was also significantly lower than that of typical Italian offenders serving equivalent sentences. Further research is necessary to understand these differences and to be able to use them to enhance treatment and rehabilitation programmes for such offenders.

\section{References}

Boden JM, Fergusson DM, Horwood LJ (2012) Alcohol misuse and violent behavior: findings from a 30-year longitudinal study. Drug and Alcohol Dependence 122: 135-141. DOI: 10.1016/j. drugalcdep.2011.09.023

Bovenkerk F (2000) "Wanted: Mafia boss" - essay on the personology of organized crime. Crime, Law and Social Change 33: 225-242.

Caretti V, Manzi GS, Schimmenti A, Seragusa L (2011) PCL-R. Hare Psychopathy ChecklistRevised [Italian edition]. Firenze, IT: OS Giunti.

Caretti V, Ciulla S, Schimmenti A (2012) La diagnosi differenziale nella valutazione della psicopatia e del comportamento violento [Differential diagnosis in the assessment of psychopathy and violent behaviours]. Rivista Sperimentale di Freniatria 136: 139-157. DOI: 10.3280/ RSF2012-001009

Dean G, Fahsing I, Gottschalk P (2010) Organized Crime. Oxford: Oxford University Press.

Di Maria F (1997) The 'mafia feeling': a transcultural theme of Sicily. Group Analysis 30: 361-367. DOI: $10.1177 / 0533316497303005$

Dickie J (2005) Cosa Nostra: A History of the Sicilian Mafia. New York: Palgrave Macmillan.

Fabj V (1998) Intolerance, forgiveness, and promise in the rhetoric of conversion: Italian women defy the Mafia. The Quarterly Journal of Speech 84: 190-208.

Grann M, Långström N, Tengström A, Kullgren G (1999) Psychopathy (PCL-R) predicts violent recidivism among criminal offenders with personality disorders in Sweden. Law and Human Behavior 23: 205-217. DOI: 10.1023/A:1022372902241

Hare RD (1998) Without Conscience: The Disturbing World of Psychopaths among Us. New York: Guilford Press.

Hare RD (2003) Hare's Psychopathy Checklist Revised (PCL-R) (2nd ed.). Technical Manual. Toronto, ON: Multi-Health Systems. 
Hare RD, Neumann CS (2008) Psychopathy as a clinical and empirical construct. Annual Review of Clinical Psychology 4: 217-246. DOI: 10.1146/annurev.clinpsy.3.022806.091452

Lieb R (2006) Developing policies for 'psychopaths': can governments learn from experience? Criminal Behaviour and Mental Health 16: 1-2. DOI: 10.1002/cbm.57

Lo Verso G, Lo Coco G (2004) Working with patients involved in the Mafia: considerations from Italian psychotherapy experiences. Psychoanalytic Psychology 21: 171-182. DOI: 10.1037/07369735.21.2.171

Lupo S (2009) The History of the Mafia. New York: Columbia University Press.

McWilliams N (2011) Psychoanalytic Diagnosis (2nd ed.). New York/London: Guilford Press.

Peters RH, Kremling J, Bekman NM, Caudy MS (2012) Co-occurring disorders in treatment-based courts: results of a national survey. Behavioral Sciences and the Law 30: 800-820. DOI: 10.1002/ bsl.2024

Rice ME, Harris GT, Cormier CA (1992) An evaluation of a maximum security therapeutic community for psychopaths and other mentally disordered offenders. Law and Human Behavior 16: 399-412. DOI: 10.1007/BF02352266

Sprecher DA. (1999) Inside the Nuremberg Trial: A Prosecutor's Comprehensive Account. Lanham: University Press of America.

Address correspondence to: Adriano Schimmenti, Faculty of Human and Social Sciences, UKE - Kore University of Enna, Cittadella Universitaria, Enna 94100, Italy. Email: adriano.schimmenti@unikore.it 